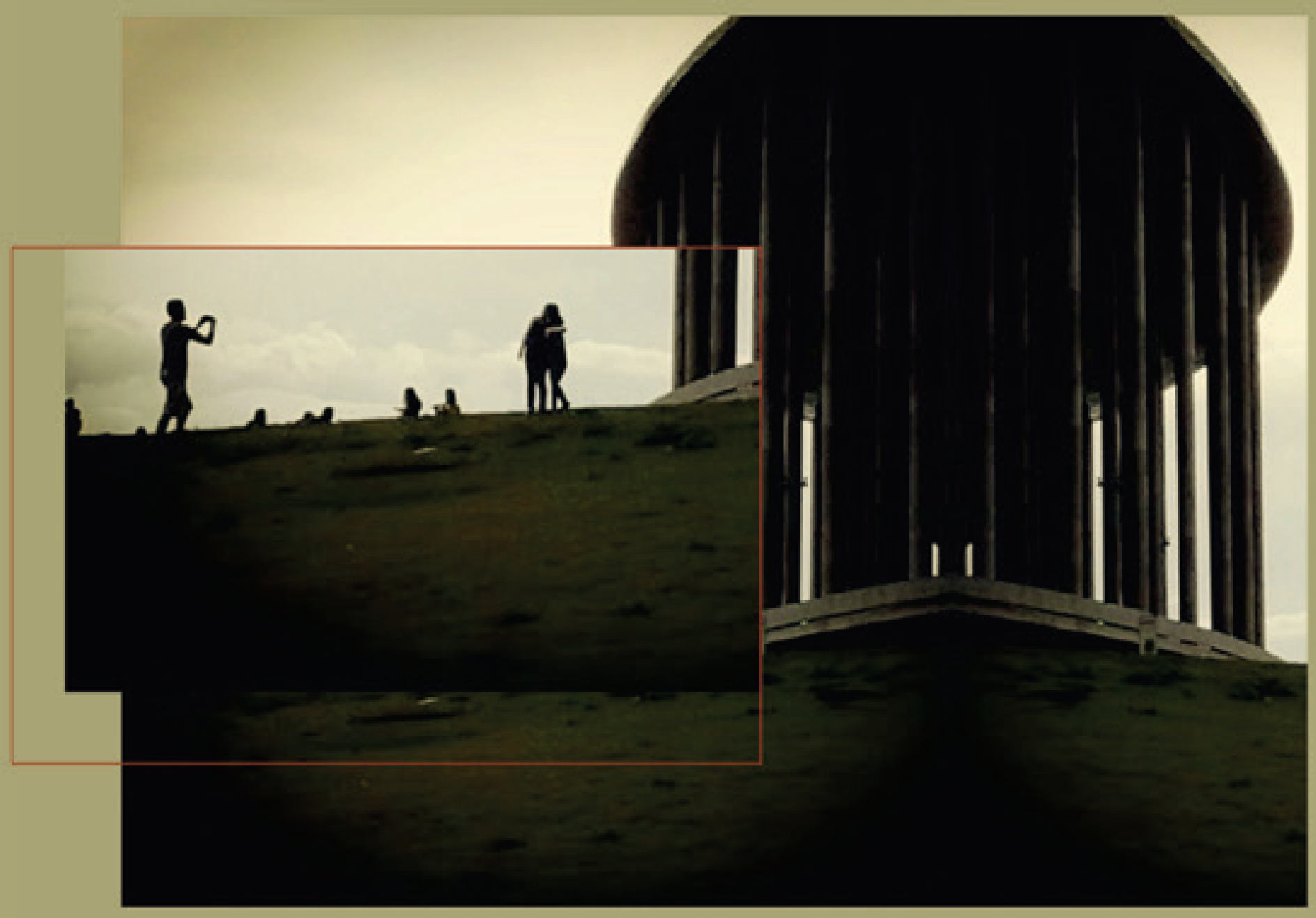




\section{Políticas Culturais Patrimoniais e Planejamento Urbano na Cidade Imperial de Petrópolis (RJ)}

Heritage cultural policy and urban planning in the Imperial City of Petropolis, RJ

Ana Paula Silva de Araújo ${ }^{1}$

1 Mestre em Planejamento Urbano e Regional pelo IPPUR-UFRJ. Geógrafa pela Universidade Estadual do Rio de Janeiro - UERJ. 


\title{
Resumo
}

A construção de uma relação mais democrática da sociedade com as políticas culturais e de preservação do patrimônio não atingiu avanços na conquista igualitária de direitos culturais. Isso passa a ser evidente na Cidade Imperial de Petrópolis (RJ), onde os instrumentos do planejamento urbano se direcionam para um tratamento meramente turístico do patrimônio reforçando a exclusão social da comunidade local. Sendo assim, o objetivo deste artigo é compreender a relação Estado e cultura em sua trajetória histórica na construção do planejamento na cidade de Petrópolis. Para isso, a metodologia seguida foi um levantamento das principais discussões sobre as políticas culturais e de preservação do patrimônio no Brasil e dos planos diretores municipais. Portanto, nas políticas de preservação do patrimônio, a hierarquia social entre o culto e o inculto nunca foi legitimamente rompida, mas reinventada nos limites do retorno a um passado imperial.

Palavras-chave: Políticas culturais e de preservação. Patrimônio. Plano Diretor Turístico. Plano Municipal de Cultura. Petrópolis (RJ).

\begin{abstract}
Building a more democratic relationship between society and cultural policies and heritage preservation has not got certain progress in the achievement of equal cultural rights. This becomes evident in the Imperial City of Petrópolis (RJ), where the instruments of urban planning are directed to a merely touristic treatment of heritage in terms of social exclusion of the local community. Thus, the objective was to understand the relationship between the State and culture in its historical trajectory in the construction of planning more precisely in the city of Petrópolis. For this, the method used was a survey of the main discussions on cultural and preservation heritage policies in Brazil and the municipal master plans. Therefore, in the policies of preservation of heritage, the social hierarchy between the cult and the uneducated was never legitimately broken, but reinvented on limits of return to a imperial past.
\end{abstract}

Keywords: Cultural and Preservation Policies. Heritage. Tourism Master Plan. Municipal Culture Plan. Petrópolis (RJ).

\section{INTRODUÇÃO}

Antes de se analisar criticamente as políticas culturais e de preservação do patrimônio histórico nacional, deve-se ter como precedentes uma reflexão do que foram as primeiras tentativas de institucionalização da memória no Brasil. Considerando a criação do Serviço do Patrimônio Histórico e Artístico Nacional (SPHAN) o ponto de partida 
para o surgimento de uma política cultural no país, não podemos desconsiderar que o cuidado com os vestígios do passado tinha os seus antecedentes mesmo antes de termos o tombamento como medida pioneira na preservação do patrimônio histórico.

A vinda da família Real para além de muitas transformações ocorridas com sua transferência para a colônia, propiciou a criação de instituições museológicas no Brasil que representou a institucionalização da riqueza, da cultura, da memória do território a ser explorado. A institucionalização do que conhecemos por patrimônio histórico teve seu início por meio da criação do SPHAN (Serviço do Patrimônio Histórico e Artístico Nacional) em 1937. O SPHAN foi a primeira iniciativa de uma política cultural no Brasil, uma inauguração da ação de preservação do patrimônio cuja identificação maior deveria ser feita com a história do Estado e tudo o que fosse aceitável para representá-lo (CHUVA, 2009).

As transformações que se seguiram na política cultural e de preservação do patrimônio histórico no Brasil - antes e durante o período do regime militar (1964-1985) e no regime democrático -, vistas em conjunto, contribuíram para a construção de instituições, programas e rearranjos de ministério, como por exemplo, o desmembramento do Ministério da Educação e Saúde, a criação do Plano de Ação Cultural, as Leis de incentivo. Do Programa de Cidades Históricas (PCH) da década de 1970 a sua posterior reformulação pelo Programa de Aceleração do Crescimento - Cidades Históricas no governo Lula, que seria a esperança do final de certas alianças neoliberais, novos avanços foram alcançados no tratamento do patrimônio no interior do planejamento urbano com uma aproximação maior entre distintas instâncias de poder.

O município de Petrópolis (RJ), localizado na Região Serrana do Estado do Rio de Janeiro, foi escolhido pela constatação de uma relação muito frágil da comunidade local com o centro histórico da cidade mencione-se entre outros aspectos: a falta de identidade; dificuldades de deslocamento a esta parte da cidade; desvalorização de outras manifestações culturais; ausência de uma participação popular nos espaços de debates relacionados às políticas culturais e aos projetos de revitalização do centro histórico. Além disso, o fato de o patrimônio ser utilizado para a sustentação da imagem de Cidade Imperial entra em contradição com sua utilização na conquista da cidadania plena pelos instrumentos ligados ao planejamento urbano petropolitano.

Neste sentido, o objetivo geral deste artigo é compreender a trajetória histórica da relação Estado e cultura no Brasil e sua projeção no planejamento urbano; como objetivo específico, pretende-se analisar os limites dos instrumentos do planejamento da cidade de Petrópolis (RJ) na promoção de uma relação mais democrática entre a comunidade local e o patrimônio. As questões centrais que nosso trabalho 
procura responder são: "Quais os entraves existentes no planejamento de cidades históricas, como Petrópolis (RJ), numa aproximação mais democrática da população local ao patrimônio?" De que forma tem sido desenhada a democracia enquanto um direito social por estes planos??

Para isso, nossos procedimentos metodológicos se basearam numa revisão bibliográfica das políticas culturais no Brasil e dos programas do governo federal de preservação do patrimônio histórico cultural no Estado Novo passando pela ditadura até chegarmos à democracia; na consulta aos planos diretores municipais de Petrópolis de 1998, e suas sucessivas revisões para acompanharmos o tratamento dado ao patrimônio nos documentos oficiais a partir da criação de um plano diretor turístico. Consultamos também o plano municipal de cultura para a coleta de informações quanto aos problemas da comunidade local em relação à aquisição de espaço nas discussões dos direitos culturais. Por fim, pequenos trechos de duas entrevistas realizadas em trabalho de campo de dois funcionários do Museu Imperial, também moradores da cidade de Petrópolis em abril de 2014.

Este breve artigo foi organizado em três partes: na primeira, traçamos uma discussão das ações antecedentes de preservação do passado no Brasil com a chegada da Família Imperial relacionadas à criação de museus, cujo divisor de águas nas instituições museológicas no país foi a criação, em 1922, do Museu Histórico Nacional. Em seguida retratamos a criação do SPHAN em duas fases iniciais marcantes de gestão que muito contribuíram na construção da política cultural no Brasil; num segundo momento, abordamos a política cultural durante a ditadura militar, vista como um dispositivo de controle social e de ativação do desenvolvimento do turismo no país, e as políticas culturais no período democrático com a entrada de um projeto neoliberal e sua permanência no governo Lula, mesmo com uma conjuntura favorável de lutas pelos direitos sociais; a terceira parte diz respeito à reformulação do Programa de Cidades Históricas, analisando a cidade de Petrópolis (RJ), e como se dá o tratamento do patrimônio histórico, em escala local, nos planos diretores municipais e no plano municipal de cultura.

\section{DOS MUSEUS DA MONARQUIA AO PATRIMÔNIO DO ESTADO NOVO}

Para Calabre (2015), a primeira iniciativa de uma política cultural no Brasil se deu com a criação do SPHAN no Estado Novo. Por outro lado, desvendar a trajetória histórica das políticas culturais e de preservação do patrimônio no Brasil centrando as análises a partir da criação deste órgão nos limitaria a refletir na existência de outras formas de produção do patrimônio no Brasil. 
É inegável que com um órgão de preservação do patrimônio nacional muitos bens históricos foram tombados em função de seu valor histórico e estético. Contudo, antes da institucionalização do patrimônio pelo Estado brasileiro houve a criação de instituições museológicas com intuito de preservar um passado sob a perspectiva de interesses voltados para o controle da riqueza da colônia a ser conquistada.

A chegada da Família Imperial Portuguesa ao Brasil causou muitas transformações na ordem pública, na infraestrutura e na habitação, principalmente, na cidade do Rio de Janeiro. As muitas transformações ocorridas destacamos a presença de certos equipamentos culturais que foram: o Real Teatro São João; a Biblioteca Nacional, o Jardim Botânico (COLOMBIANO, 2007); a criação do primeiro museu nacional em 1818 por D. João Vl; o Museu Imperial, um museu de história natural chamado posteriormente na República Velha por Museu Nacional (SANTOS, 2004). No que toca à criação de museus no Brasil, até o fim do século XIX, tínhamos o Museu Naval e Oceanográfico (1868); o Museu da Academia Nacional de Medicina (1898); o Museu Nacional, citado anteriormente; o Museu Paulista; e o Museu Goeldi (1866) (SANTOS, 2004).

A presença da Metrópole na cidade do Rio de Janeiro contribuiu para a consolidação de uma centralidade política e cultural na colônia em função das instituições representativas da burocracia do Estado português. Neste sentido, os museus criados enquanto instituições-memória também fizeram parte desta centralidade, porém não da forma como os conhecemos na contemporaneidade. Os museus da Europa tinham uma natureza enciclopédica, pois procuravam expor as riquezas culturais e naturais do mundo. No Brasil, por outro lado, o museu, inicialmente, era uma instituição criada para se guardar a riqueza natural do Império, o que revelaria uma preocupação em preservar o passado não da Colônia, mas da Metrópole. Além disso, o conhecimento das riquezas e da cultura do território explorado eram monopolizadas e resguardadas para estudos nestas instituições (SANTOS, 2004).

Com a criação do Museu Histórico Nacional em 1922 por Gustavo Barroso, os museus nacionais entram numa nova era passando a guardar objetos representativos da história da nação sob a perspectiva de uma elite, deixando de fora as classes sociais mais populares (SANTOS,2004). Esta formação do acervo dos museus ditada por Gustavo Barroso que privilegiava o patriotismo, o conservadorismo, influenciou outras instituições museológicas pelo Brasil (SANTOS, 2004) e o SPHAN. Criado em 1937, ele fez parte da construção da nação pelo regime do Estado Novo. Isso também é retratado por Gonçalves (1988, p. 267), quando afirma que

(...) Desse modo, muitos dos bens culturais que compõem um patrimônio estão associados ao "passado" ou à "história" da nação. Eles são classificados como "relíquias" ou "monumentos". Assim como a 
identidade de um indivíduo ou de uma família pode ser definida pela posse de objetos que foram herdados e que permanecem na família por várias gerações, também a identidade de uma nação pode ser definida pelos seus monumentos - aquele conjunto de bens culturais associados ao passado nacional. Estes bens constituem um tipo especial de propriedade: a eles se atribui a capacidade de evocar o passado e, desse modo, estabelecer uma ligação entre passado, presente e futuro. Em outras palavras, eles garantem a continuidade da nação no tempo.

A identidade da nação brasileira deveria ser construída de modo que o bem cultural tombado a representasse diante do mundo como sendo pertencente ao que se considerava como modernidade. $\mathrm{O}$ monumento do passado nacional daria condições para se eternizar no tempo e no espaço a memória social legitimadora da nação que se pretendia construir. A atuação do SPHAN, centrada numa lógica de produção da cultura nacional pelo próprio Estado, contribuiu para que o Brasil construísse o seu patrimônio histórico cultural por meio do tombamento, segundo critérios estabelecidos. Este órgão de proteção do patrimônio histórico nacional teve duas fases de gestão marcantes que nos permitem pensar como a cultura foi tratada inicialmente no Brasil enquanto política de Estado.

Num primeiro momento, o SPHAN teve como primeiro diretor Rodrigo Melo Franco de Andrade atuando de 1937 a 1967. Nesta fase o discurso deste órgão estava direcionado para um projeto de construção da nação; o Estado deveria ser o guardião do patrimônio de um povo que não tinha consciência de sua importância. Durante as décadas de 1930 e 1940, o SPHAN concentrou esforços em tombar bens históricos nos estados de Minas Gerais, Rio de Janeiro, São Paulo, Rio Grande do Sul, Bahia, Pernambuco, Paraíba, Sergipe, Alagoas, Espírito Santo e Goiás (CHUVA, 2009). Sua preocupação era assegurar a unidade nacional construindo o patrimônio como algo de interesse comum. Esta fase pode ser caracterizada pelo que foi a "rede mineira" (CHUVA, 2009) de agentes, quando o SPHAN determinou que o patrimônio arquitetônico mineiro fosse o padrão de qualidade a ser seguido (CHUVA, 2009) e tivesse na arquitetura barroca um dos principais símbolos da memória nacional.

Este projeto nacional hegemônico adquire uma nova roupagem durante a segunda e terceira décadas do século XX quando, conforme Gonçalves (2002), a elite cultural e política ligada ao Modernismo e ao Estado Novo tinha os padrões europeus como guia para se construir uma cultura brasileira autêntica. Em outras palavras, a autenticidade da cultura brasileira deveria ser conquistada a qualquer custo, e para isso o padrão europeu era tido como modelo do que era considerado belo e monumental ou do que interligaria nossas raízes à civilização. Isso justificaria a posição 
da arquitetura barroca mineira na política federal de preservação do patrimônio no Brasil, o que representaria a influência direta de nossos colonizadores.

Em suma, na gestão de Rodrigo Melo Franco de Andrade, na primeira fase do SPHAN, tivemos uma política elitista de preservação do patrimônio e essencialmente técnica no tombamento dos bens culturais privilegiando certas áreas em detrimento de outras, realizada por um governo forte e centralizador que perseguia um projeto de modernização. O Estado, na posição de "guardião do interesse nacional", deveria promover a preservação do patrimônio histórico cultural (CHUVA, 2009).

Na fase seguinte iniciada em 1979 e correspondente à gestão de Aloísio Magalhães muitas foram as transformações sentidas pelo SPHAN e pelo patrimônio nacional. Neste período, a ideia de "cultura brasileira" estava mais centrada no presente do que no passado; para ele, os "bens culturais" seriam a vida cotidiana da população. Um aspecto relevante era a valorização da diversidade cultural da sociedade brasileira, afirmando a necessidade de se desenvolver um diálogo dos profissionais ligados ao patrimônio cultural com a comunidade local (GONÇALVES, 2002).

Fazendo um grande balanço desta segunda fase do SPHAN, consideramos importante a preocupação em resguardar as outras dimensões do patrimônio cultural nacional, sua diversidade e cultura popular (GONÇALVES, 2002). Por outro lado, por mais que o tratamento do patrimônio tivesse sido ampliado, as mudanças decorrentes ainda se encontravam amarradas a um Estado centralizador e a uma elite culta nos padrões europeus. O fato era que o SPHAN, em suas significativas gestões, contribuiu para a criação dos limites de uma nova área cultural para o Brasil. Além disso, proporcionou a sua inserção na comunidade internacional como uma nação a preservar os seus bens culturais (FALCÃO, 1984).

\section{A POLÍTICA CULTURAL E DE PRESERVAÇÃO NO BRASIL: DA RE- PRESSÃO À DEMOCRACIA}

A ditadura militar no Brasil tinha a cultura como um forte elemento propulsor do desenvolvimento e da segurança nacionais. Logo, esta área sofreu transformações com a criação de novos programas para o tratamento do patrimônio, como a criação do $\mathrm{PCH}$ e etc. Na fase de abertura democrática, novos desmembramentos estruturais foram realizados desmontando o que se havia construído no período anterior e alterando a política cultural de preservação para a entrada de um projeto neoliberal. O governo Lula (2003-2010), associado à esperança de mudanças inaugura uma nova política cultural e do patrimônio, promovendo novos avanços. 
Com isso, uma nova política cultural e de preservação do patrimônio é inaugurada assumindo o lugar das leis de incentivo, assim como, a criação do PAC- Cidades Históricas, promovendo novos avanços na luta por direitos sociais ainda não conquistados em sua plenitude pelas velhas relações de poder, nas quais o patrimônio nunca deixou de ser visto como um recurso.

Durante a gestão do general Emílio Gastarrazu Médici (1969-1974), foi elaborado o Plano de Ação Cultural (PAC) que possibilitou o acesso ao crédito financeiro e político para certas áreas culturais que não recebiam verbas do Estado. Tal plano tinha como uma de suas três metas a preservação do patrimônio histórico e artístico nacional (MICELI, 1984). Podemos dizer que a política cultural formulada no regime ditatorial no Brasil era direcionada para um projeto político que assegurasse a segurança nacional e o desenvolvimento tendo a cultura como elemento decisivo. Para Cohn (1984, p. 90),

(...) não é suficiente a conservação do patrimônio acumulado. É preciso "promover o seu constante acréscimo", para "assegurar à cultura brasileira presença influente no âmbito internacional e ampla capacidade de assimilação discriminatória dos contingentes recebidos de outras culturas. A questão básica, portanto, acaba sendo a da garantia da formação de uma "personalidade nacional forte e influente". Por isso, "o deperecimento do acervo cultural acumulado ou o desinteresse pela contínua acumulação de cultura representariam indiscutível risco para a preservação da personalidade brasileira e, portanto, para a segurança nacional". Dessa forma, a "intensificação das atividades culturais está chamada a representar uma das ações fundamentais" naquilo que realmente interessa, que é a "estratégia de desenvolvimento", que tem por significado "a presença do Estado, como elemento de apoio e estímulo - que não se confundirá com coerção ou tutela, na integração do desenvolvimento cultural dentro do processo global de desenvolvimento brasileiro.

A preservação do patrimônio histórico cultural não se mostrava suficiente para a construção de uma cultura brasileira perante as demais nações; a meta de um desenvolvimento e segurança nacionais se mostrariam possíveis no investimento da formação de uma "personalidade nacional forte e influente". Sendo assim, vale a pena ressaltarmos que o Programa das Cidades Históricas (PCH), na década de 1970, voltou-se para a reconstrução das cidades históricas do Nordeste, que se constitui como uma tentativa de o governo militar retomar o desenvolvimento econômico seguindo as propostas do I e II PNDs ${ }^{2}$ (CORREIA \&FARIA, 2011). Este foi o primeiro programa do governo federal a investir intensamente na preservação do patrimônio cultural ligado à lógica do desenvolvimento urbano e regional.

2 I e II Plano Nacional de Desenvolvimento. 
De acordo com Correia e Faria (2011), o PCH foi criado a partir das decisões do "Compromisso de Brasília," em abril de 1970, que foi o I Encontro dos Governadores de Estado. No próprio documento, mais precisamente na página 1 , podemos ter acesso ao que ficou determinado como sendo a "inadiável necessidade de ação supletiva dos estados e municípios à atuação federal no que se refere à proteção dos bens culturais de valor nacional" (COMPROMISSO DE BRASÍLIA, 1970) Propôs-se uma política de preservação do patrimônio numa ação integrada de todas as esferas de poder. Em seguida, com o encontro que ficou conhecido por Compromisso de Salvador, ocorrido em 1971, além de uma proposta para a criação de um Ministério da Cultura, o que foi defendido no encontro anterior em Brasília acabou sendo reafirmado, e ainda defendeu-se um planejamento turístico para que se divulgasse as potencialidades naturais e culturais do país. Neste documento ficou muito evidente uma preocupação para com a preservação e valorização dos monumentos naturais e culturais protegidos por lei para se alcançar um desenvolvimento do turismo.

O Programa das Cidades Históricas (PCH) serviu para que saibamos os caminhos que estavam sendo tomados pela política de preservação do patrimônio cultural em conformidade com o que se discutia no cenário internacional no que diz respeito a aproximação do patrimônio ao turismo. Contudo, segundo Correia e Faria (2011), o PCH não foi eficiente em sua tentativa de distribuição regional de renda via o patrimônio por conta de desarticulações institucionais dificultando a ação conjunta entre as diferentes instâncias de poder.

O fim da ditadura e a chegada da fase de democratização do Brasil não alterariam o cenário de instabilidade institucional das políticas culturais. No que toca à política cultural, as décadas de 1980 e 1990 se caracterizaram pelas leis de incentivo, que abririam espaço para que, nessa área, o Estado fosse integralmente substituído pelo mercado. Na década de 1980, a área da cultura no Brasil pode ser caracterizada pela criação do Ministério da Cultura, em 1985, porém, no repasse de verbas estavam mais direcionadas em sua grande parte para o Ministério da Educação. Com isso, frente a esta retração de recursos por conflitos internos, o presidente Sarney inaugurou a Lei n. 7.505 de incentivo à cultura durante a gestão do ministro Celso Furtado (CALABRE, 2005). Para Rubim (2007), esta lei radicalizou as formas de financiamento da cultura, porque o mercado realizaria o financiamento direto dos projetos de cultura.

Aprofundando essa política, o governo Fernando Henrique Cardoso (1994-2002) acabou como um grande beneficiário das políticas culturais por meio da concessão de financiamentos pelo Estado das leis de incentivo, o governo Fernando Henrique Cardoso acabou por implantar, conforme palavras de Rubim (2007, p. 109), "de modo menos tosco e mais enfático" o projeto neoliberal no Brasil. Estas leis de incentivo à cultura passaram a definir a própria política cultural do país benefician- 
do as empresas de marketing e revelando a ausência de uma verdadeira política cultural no Brasil (RUBIM, 2007) e (MORAES, 2009).

No início dos anos 2000, o Brasil sofria com os reflexos de uma situação de esgotamento das ações neoliberais praticadas na América Latina em função de sucessivas crises financeiras. A hegemonia se rompia e o grupo das maiorias, sempre excluídas, passava a adquirir força na reivindicação de seus direitos elegendo políticos contrários às pressões exploradoras externas que dominavam anteriormente (MORAES, 2009). É neste contexto que se dá a vitória de Luís Inácio Lula da Silva para a presidência da República no Brasil. No campo da cultura, a eleição de Lula demonstrou uma necessidade de se realizarem novas alianças políticas e partidárias para a incorporação de pontos de interesse que contemplassem o processo de ampliação do conceito de cultura em curso desde a década de 1970, e que vinha incorporando novos agentes na agenda pública. Contudo, por mais que a incorporação de novos e diferentes atores sociais se mostrasse necessária, isso não fazia parte da agenda política do Partido dos Trabalhadores (MORAES, 2009).

As mudanças ocorridas durante o governo Lula garantiram certos direitos sociais, entretanto, ainda pairava uma força vinda dos interesses financeiros não comprometidos com o bem-estar da sociedade brasileira. Isso também foi sentido pelas políticas culturais que ainda não passaram por profundas rupturas sociais, pois ainda são vistas, pelo Ministério da Cultura, como um "tesouro", "um ativo social e econômico", expressões de Gil (2005). Este discurso que põe a cultura como um fator de mudança, mas ainda destinada a perpetuar velhas relações de poder está presente nos instrumentos do planejamento urbano de municípios que buscam aprimorar a sua reprodução imaterial no que diz respeito a sua imagem no mercado. Este vem a ser o exemplo de uma Cidade Imperial como Petrópolis (RJ), que inserida no Programa de Aceleração do Crescimento (PAC) - Cidades Históricas, vem articulando os seus planos diretores municipais para a manutenção da Marca Petrópolis entre as cidades da Região Serrana do Estado do Rio de Janeiro em detrimento da construção de uma identidade mais próxima da realidade e memória de seus moradores.

\section{OS LIMITES DO PLANEJAMENTO DA CIDADE IMPERIAL DE PETRÓPOLIS (RJ)}

Conforme os trabalhos de Megumi; Uemura; Sutti e Diogo (2011), foram estabelecidos Planos de Ação para os 141 municípios que tivessem patrimônio cultural tombado ou registrado nacionalmente. $O$ objetivo destes planos é estabelecer uma ação coordenada entre as distintas instâncias de poder e a sociedade civil para a constru- 
ção de um Sistema Nacional do Patrimônio Cultural. Ainda segundo Megumi; Uemura; Sutti e Diogo (2011), tais planos possuem uma grande relevância por estarem em contato com os recursos advindos do PAC-Cidades Históricas. Consequentemente, a cidade que concentrasse maior parte destes investimentos indicaria um valor simbólico maior na cultura brasileira e na promoção do desenvolvimento do país.

No caso das cidades que já tivessem um Plano Diretor, seus projetos de proteção do patrimônio cultural só seriam aprofundados nestes Planos de Ação. Estes contribuíram para o fortalecimento dos órgãos gestores do patrimônio cultural numa atuação integrada no território através de um contato mais direto com os instrumentos do planejamento urbano, como o plano diretor, o plano de habitação, o plano de reabilitação de áreas urbanas centrais e os fundos municipais (MEGUMI; UEMURA; SUTTI e DIOGO, 2011). Isto chega a ser um reflexo dos pontos positivos alcançados pelo PAC-Cidades Históricas no que diz respeito a uma articulação institucional possível que contribuiu para a criação de uma estrutura em que o patrimônio arquitetônico histórico urbano recebesse investimentos para a sua preservação na escala local. Neste sentido, Petrópolis fez parte das 15 cidades fluminenses que comporiam o Plano de Ação para as Cidades Históricas em 2010. Os municípios seriam contemplados com um investimento de $\mathrm{R} \$ 20$ milhões para executarem estes planos. No caso de Petrópolis, foi apresentada uma proposta de revitalização de três áreas históricas como forma de inserção do município no Programa de Cidades Históricas.

Os recursos provenientes deste programa para projetos de requalificação foram direcionados para áreas históricas selecionadas. Isso pode ser considerado um reflexo de seria o tratamento do patrimônio histórico nos municípios pelos seus planos diretores e pelos seus planos municipais de cultura. No caso de Petrópolis, tomamos como ponto de partida as análises de seu plano diretor de 1998 e suas sucessivas revisões. Este plano diretor municipal estava voltado para os seguintes objetivos: incremento dos fluxos turísticos; aumento da estada dos seus visitantes; consolidação de sua posição de destaque de destino turístico; fortalecimento de sua imagem turística como Cidade Imperial (CUNHA, 2008).

Na versão do plano diretor turístico de 2009 ainda fica evidente a proposta de criar em Petrópolis a identidade para de principal destino turístico da Região Serrana do Rio de Janeiro (CUNHA, 2008). Neste plano foi determinada a manutenção da Marca Petrópolis, baseada na tentativa de se reconstruir todo um cenário do passado imperial que a cidade carrega em seu simbolismo e em seu conjunto arquitetônico histórico urbano. Isso se evidencia no posicionamento deste plano em relação ao setor do comércio, que deveria ser estruturado para atrair mais entretenimento; estabeleceu-se a desobstrução do trânsito no centro histórico proibindo a 
passagem de caminhões e ônibus; propôs-se a construção de edifícios garagens no próprio centro, valorizando o bem-estar do consumidor. Este documento mostrou em suas propostas a ausência de uma política de preservação do patrimônio para o município. O centro histórico de Petrópolis (RJ) foi visto apenas como um atrativo turístico a ser preservado através de medidas de policiamento, limpeza das ruas, restauração de imóveis históricos, adoção de projetos que mantivessem a marca de Cidade Imperial diante das demais cidades da Região Serrana (PLANO DIRETOR MUNICIPAL DE PETRÓPOLIS, 2009).

Em seguida, o Plano Petrópolis Imperial, aprovado pela lei n. 6.771 de julho de 2010, para o ano de 2010 a 2019, mostra uma preocupação constante em se construir um marketing urbano para uma inserção privilegiada da cidade no mercado turístico. Neste plano, o patrimônio era tratado como uma potencialidade do município em promover o seu crescimento econômico. E além disso, ainda se chegou a tratar superficialmente de uma suposta cidadania cultural autônoma e desvinculada de uma proposta anterior de conscientização dos cidadãos quanto as suas responsabilidades diante da promoção do turismo na cidade. E por fim, ficou evidente em todo o documento, a preocupação em se resguardar de forma cênica todos os símbolos que ajudassem a sustentar a imagem de Cidade Imperial de Petrópolis.

Numa das revisões mais recentes do Plano Diretor Municipal de Petrópolis em 2013, podemos constatar uma primeira menção às políticas culturais associadas à defesa do patrimônio natural, construído e imaterial. Com isso, este plano diretor defende que a preservação do patrimônio e da memória estivessem ligados às políticas culturais detentoras de uma abordagem mais ampla da ideia de cultura. Neste documento fica ainda mais evidente a ausência de uma política de preservação do patrimônio, onde ações urbanísticas pontuais acabam predominando, como os projetos de requalificação do centro histórico de Petrópolis em detrimento de outras localidades. No discurso deste plano diretor municipal, a política cultural e de turismo não são mais associadas somente ao primeiro distrito e do centro histórico, mas outras localidades devem ser contempladas nos projetos de reurbanização a serem propostos.

A participação da população petropolitana sempre é tratada nestes planos como algo voltado a uma conscientização e capacitação da prática do turismo na própria cidade. Na realidade, a participação popular na criação do Museu Imperial, no Projeto Petrópolis de revitalização de seu centro histórico e em demais situações, se mostra um tanto ausente se analisado com mais cuidado. A justificativa para isso se encontra no que foi o "Parecer Conclusivo e Final da Comissão Especial de Estudo e Revisão do Plano Diretor de Petrópolis de 2013" consta que o problema não está na ausência da participação popular na tomada de decisões, mas em sua presença que 
se mostra um tanto deficiente. A participação popular não é plena e nos revela uma falta de politização social no que diz respeito ao desconhecimento das pautas que contemplam a ideia de cidadania como um todo. Em outras palavras, nas audiências públicas são levantados certos problemas concernentes ao cotidiano de uma grande parcela da população que não conhece a importância de certos instrumentos como o Plano Diretor, assim como, a falta de consciência em reivindicar os seus direitos culturais enquanto um direito social básico como qualquer outro ligado à cidadania.

O Plano Municipal de Cultura de Petrópolis de 2010, marcado por um forte incentivo à participação popular, demonstra, através de um diagnóstico elaborado a partir da realidade do município, algumas lacunas advindas do tratamento do patrimônio pelo planejamento urbano e suas implicações na relação da comunidade com a construção da memória coletiva. Este plano em seu diagnóstico mostra a necessidade de se superar as desigualdades internas do município; mencione-se, neste sentido, a falta de integração entre os distritos como espaços culturais na formulação de propostas de políticas públicas, principalmente, na área da cultura. Isso ocorre em função de uma relação fragmentada entre as várias identidades culturais que não encontram espaços de diálogos, de garantia de direitos e de diversidade cultural nas áreas de requalificação urbana e naquelas privilegiadas pelos planos diretores municipais. É patente a falta de apoio às outras manifestações culturais por conta de uma certa predominância da "grande arte" em detrimento da cultura popular desqualificando, com isso, a produção artística local, do cotidiano. A marca de Cidade Imperial de Petrópolis - sustentada por um planejamento urbano que, através dos planos diretores e de requalificação urbana, atua seletivamente no espaço para criar um cenário da Monarquia - inibe as demais partes da população e os movimentos sociais que se sentem excluídos socialmente não apenas pela atuação pontual destes investimentos, mas também por uma falta de um sentimento de identidade em relação à história e memória da própria cidade que pertencem.

Este documento levanta certas propostas cujo guia para se chegar um ideal possível é a reivindicação do que se considera como sendo direito cultural. Os direitos culturais - vistos como um direito social básico a ser reconhecido enquanto tal - possibilitariam, o uso dos vestígios do passado, a construção igualitária de uma memória coletiva no presente que oferecesse condições para a projeção de um futuro possível para o exercício de uma cidadania cultural. Ao nos depararmos com a realidade, os instrumentos do planejamento de uma cidade como Petrópolis (RJ) adaptam em seus discursos uma democratização da cultura, porém, uma cultura erudita suprema necessitaria ser incorporada pelas demais classes sociais. A cultura deveria ser acessível a todos como um direito social básico na construção mercado- 
lógica de uma Cidade Imperial das Américas. Para isso, a concentração dos investimentos no embelezamento estético e preservação do principal centro histórico de Petrópolis deve contribuir para manter uma imagem que reflita o período Imperial no Brasil. Entretanto, as manifestações culturais em outras localidades sinalizando possibilidades de se contar a memória da cidade não parecem ser interessantes, nem incorporadas por um Estado que não quer ser representado por todos. Assim, as propostas de um Plano Municipal de Cultura que defende uma democracia cultural - onde todos são vistos não somente como consumidores, mas como produtores no processo cultural - apesar dos reais obstáculos a serem enfrentados não estão sintonizados com o plano diretor municipal. Isso pode ser notado claramente nos relatos de dois funcionários do Museu Imperial e também moradores da cidade de Petrópolis (RJ) percebidas em duas entrevistas realizadas em abril de 2014.

Em contraposição à fala do diretor do Museu Imperial, para quem “(...) inconcebível que ainda haja um petropolitano que ainda não conheça o Museu Imperial" está a posição da museóloga responsável:

“(...) Tem que deixar de ser só turismo. (...) Tem muita gente que mora em Petrópolis, tanto adulto como estudante, que nunca colocou os pés no Museu Imperial, nem no palácio, como uma visita "turística" e nem como pesquisa. (...) Nem vêm aqui.(...) Não tem o hábito. Isso é uma das coisas que me incomoda como museóloga. Museu é base de educação! (...) É complemento de sala de aula(...)"

Nestas duas falas um tanto divergentes nos deparamos mais uma vez com a questão do distanciamento da população local em relação a um patrimônio histórico em específico, o Museu Imperial. Para o diretor desta instituição, a população local não é vista como distante do Museu Imperial, que representa a história do Estado nacional brasileiro e a memória da própria cidade. No entanto, a museóloga em suas afirmações mostra perspectiva distinta e ainda aponta dois problemas: a predominância da atividade do turismo; e a falta de articulação com a educação, também apontada pelo Plano Municipal de Cultura. A justificativa para isso estaria na forma como o patrimônio é visto por estes dois atores sociais, e também como cada um deles vê não apenas o museu em si, mas o centro histórico.

Em mais uma das muitas falas do diretor, o museu é tido como "referência do turismo da cidade." Uma das para bases para tal afirmação é o projeto Som e Luz que realiza espetáculos no museu reproduzindo uma festa da corte nos tempos do Império e consequentemente acaba por atrair um grande público. E como o centro histórico não tem uma vida noturna, este projeto acaba dinamizando o setor hoteleiro e o de serviços. Logo, o centro histórico é visto como um espaço de consumo cultural, onde o Museu Imperial é um de seus captadores de público. O mesmo 
acontece ao se enxergar o museu como um grande atrativo de turistas nos megaeventos esportivos. Contudo, na percepção da museóloga, a apropriação pela grande massa do centro histórico, do Museu Imperial de Petrópolis, e de qualquer programação cultural é comprometida por aquilo que os planos de revitalização proporcionaram, e pela forma como o plano diretor trata turisticamente o patrimônio no município. O que ficou marcado na fala da museóloga foi a questão da dificuldade de mobilidade da população, não apenas no que diz respeito ao transporte coletivo:

"Como é que você vai ter um concerto de piano às sete horas da noi-
te num local onde você não tem onde parar o carro? Você não tem
estacionamento próximo. O ônibus é difícil. (...) Essas atividades, se-
jam dentro de museus, de cinemas, como uma atividade educativa.
Como não é vista como uma atividade educativa, o governo estadual,
municipal, federal, seja lá o que for não se vê obrigado a participar."

E ainda acrescenta mais à frente dizendo que: "Petrópolis é uma cidade que tem uma dificuldade enorme de ônibus. Transporte urbano aqui é péssimo. (...) É péssimo no sentido de linhas. (...) Os ônibus aqui só passam de três em três horas." Portanto, podemos perceber - diante das lacunas quanto ao tratamento do patrimônio nos planos diretores municipais de Petrópolis (RJ), e do que foi levantado pelo Plano Municipal de Cultura - na experiência destes dois personagens ligados tanto ao Museu Imperial quanto ao centro histórico as dificuldades na vida cotidiana da população para uma vivência mais autônoma e construção de sua própria cidade.O esvaziamento do centro histórico não deve ser combatido essencialmente por turistas, mas por quem também faz parte da construção da memória da cidade.

\section{CONSIDERAÇÕES FINAIS}

A tentativa de se resguardar o passado por meio do que foram os primeiros museus no Brasil até a formação de algo mais abrangente como a política federal de preservação e de cultura nos revela uma ideologia do Estado construída dinamicamente ao longo do tempo e projetada sobre o território nacional. Uma ideologia voltada para resguardar os recursos de uma colônia a ser explorada e posteriormente direcionada para a preservação do passado como um recurso do Estado nação. Um recurso que contribuiria para a construção de uma História e memória para fazer uma nação moderna frente às outras. Posteriormente, a preservação do patrimônio histórico cultural - passando de recurso de legitimação da identidade nacional para o status de recurso econômico e de desenvolvimento da atividade do turismo - compôs o discurso das políticas culturais implantadas por um Estado autoritário e produtor da cultura brasileira. 
O SPHAN, em suas duas significativas gestões, contribuiu enquanto embrião da política cultural no Brasil para a manutenção do controle do Estado por meio da cultura. Na direção de Rodrigo Melo Franco de Andrade, ao se promover a construção do patrimônio no Brasil tivemos o fortalecimento de uma "rede mineira" na prática de tombamento e a separação evidente entre o erudito e o popular. Na fase de Aloísio Magalhães, a ideia de patrimônio foi ampliada, a cultura popular e a inserção do cotidiano valorizadas. Estas foram as duas primeiras fases primordiais do SPHAN cujas ações referentes ao tratamento do patrimônio culminaram no surgimento de outras medidas de se preservar a cultura e de se perpetuar o controle e a hierarquia social existentes no Brasil.

O Programa de Cidades Históricas (PCH) de 1973 e sua posterior reformulação no PAC-Cidades Históricas representam avanços em seus respectivos contextos de surgimento e implantação na preservação do patrimônio histórico no Brasil. Aquele por ter sido uma primeira iniciativa governamental de se preservar centros históricos do Nordeste e ainda redirecioná-los para a atividade do turismo; o segundo por ter conquistado uma articulação entre as distintas esferas do poder promovendo a preservação do patrimônio na escala local numa ação conjunta com instrumentos do planejamento urbano, o que não foi possível em sua primeira versão no regime militar. Nesta ação conjunta os planos diretores municipais passam a ter que incorporar o patrimônio como pauta de um programa federal de preservação; a cidade de Petrópolis se projeta em sua materialidade no que diz respeito ao seu conjunto arquitetônico tombado na corrida para a aquisição de investimentos.

Ao observarmos o tratamento do patrimônio histórico nos planos diretores municipais de Petrópolis (RJ), verificamos a sua associação à atividade do turismo como um dos meios mais eficazes para que a cidade se transforme numa liderança em relação às demais na Região Serrana. Do plano diretor de 1998 e de suas revisões, acompanhamos uma evolução em que o patrimônio passa a não ser tido apenas como um sinônimo do desenvolvimento do turismo, mas como uma conquista de direitos culturais, atrelado ao meio ambiente, separado em material e imaterial, incorporado à paisagem. Estas mudanças não somente nos revelariam a incidência de uma tendência maior na apropriação de certos conceitos no que diz respeito ao patrimônio, o que não é o nosso objetivo aqui, mas também nos mostra a ausência de uma política patrimonial autônoma.

A ausência, revelada pelo Plano Municipal de Cultura, no que toca à participação popular problematiza os limites de reconstrução do passado impostos pelos instrumentos do planejamento urbano. Limites em que o retorno ao passado se dá numa relação de poder no presente; os agentes sociais produtores do espaço ini- 
bem o sentimento de identidade e de inclusão social das classes sociais menos desfavorecidas promovendo a seletividade de investimentos na própria cidade para a construção de sua imagem mercadológica. Portanto, na relação Estado e cultura, o passado resgatado pelas políticas de cultura, de preservação do patrimônio e pelos planos diretores no planejamento de cidades históricas, como Petrópolis (RJ), acaba contribuindo para o afastamento não apenas de uma classe social mais popular, mas de outras possibilidades de criação, de economias menos excludentes, outras formas de se fazer e de viver a cidade (RIBEIRO, 2004).

\section{REFERÊNCIAS}

ABREU, Maurício de Almeida Abreu. Paradoxos da Modernidade: o Rio de Janeiro do período joanino, 1808-1821. In: Fridman, F. (Org.); Haesbaert, R. (Org.). Escritos sobre Espaço e História. Rio de Janeiro: Garamond, 2014, pp.359-398.

AMBROZIO, Julio Cezar Gabrich. Viagem, turismo, vilegiatura. In: Geousp: Espaço e Tempo, São Paulo, n.18, pp.105-113, 2005. Acesso em 15 set. 2014.

AZEVEDO, Marlice N. S. de. O espaço fluminense e a intervenção urbana no Estado Novo. In: REZENDE, V.F. (Org.); FERNANDES, Ana (Orgs.). Urbanismo na Era Vargas: a transformação das cidades brasileiras. Niterói: Ed.uff/Intertexto, 2012, pp.177-196.

CALABRE, Lia. Política cultural no Brasil: um histórico. I Enecult. 2005. Disponível em: <http://www.cult.ufba.br/enecul2005/LiaCalabre.pdf>. Acesso em 17 abr. 2015.

COHN, Gabriel. A concepção oficial da política cultural nos anos 70. In: Miceli, S (Org.). Corpo e alma do Brasil. São Paulo: Difel, 1984, pp.85-96.

COLOMBIANO, Raquel Muniz. As espacialidades das políticas culturais: a cidade do Rio de Janeiro nos anos 1990 e 2000. Dissertação de mestrado. Rio de Janeiro: Ippur, 2007.

CORREIA, Sandra R.; FARIA, Rodrigo S. de. O Plano de Cidades Históricas (PCH) no planejamento governamental brasileiro e o desenvolvimento urbano e regional (19731979). Revista de Pesquisa em Arquitetura e Urbanismo, 2011, iau-usp, pp.20-26. Disponível em: <http://www.revistas.usp.br/risco/article/viewFile/45502/49111>. Acesso em 17 abr. 2015.

CHUVA, Márcia R. R.. Os arquitetos da memória: sociogênese das práticas de preservação do patrimônio cultural no Brasil (anos 1930-1940). Rio de Janeiro: Ed. ufrj, 2009. CUNHA, Paloma. Gestão pública municipal do turismo e sua aplicabilidade: plano diretor de turismo de Petrópolis. Monografia de graduação. Niterói: uff, 2008. 
CUNHA Filho, F. H.. Integração de políticas culturais: entre ideias de aliança e sistema. In: CALABRE, L. (Org.) Políticas culturais: teoria e práxis. São Paulo: Itaú Cultural/ Rio de Janeiro: Fundação Casa de Rui Barbosa, 2011, pp.118-129. Disponível em: <http://d3nv1jy4u7zmsc.cloudfront.net/wp-content/uploads/2013/04/Politica-Culturais-Teoria-e-Praxis.pdf>. Acesso em 17 abr. 2015.

FALCÃO, Joaquim. Política cultural e democracia: a preservação do patrimônio histórico e artístico nacional. In: Miceli, Sergio (Org.). Corpo e alma do Brasil. São Paulo: Difel, 1984, pp.21-39.

FRIDMAN, Fania. De núcleos coloniais a vilas e cidades: Nova Friburgo e Petrópolis. 2001. Disponível em: <http://www.anpur.org.br/revista/rbeur/index.php/anais/article/view/2187>. Acesso em 14 mar. 2014.

GONÇALVES, José Reginaldo. A retórica da perda: os discursos do patrimônio cultural no Brasil. 2 ed. Rio de Janeiro: Edufrj/Ministério da Cultura, 2002.

. Autenticidade, memória e ideologias nacionais: o problema dos patrimônios culturais. Estudos Históricos. Rio de Janeiro, v.1, n.2, 1988, pp.264-275.

GIL, Gilberto. Uma nova política cultural no Brasil. Revista do Rio de Janeiro, n.15, jan.-abr. 2005, pp.103-110. Disponível em: <http://www.forumrio.uerj.br/documentos/revista_15/15_dossie_GilbertoGil.pdf>. Acesso em 17 abr. 2015.

LE GOFF, Jacques. História e memória. São Paulo: Ed. Unicamp, 1990, pp.423-484. Coleção Repertórios. Disponível em: <http://memorial.trt11.jus.br/wp-content/ uploads/Hist\%C3\%B3ria-e-Mem\%C3\%B3ria.pdf>. Acesso em 16 abr.2015.

LOWENTHAL, David. Como conhecemos o passado. Projeto História. São Paulo (17), nov. 1998. Disponível em: <http://revistas.pucsp.br/index.php/revph/article/ view/11110>. Acesso em 16 abr. 2015.

MEGUMI, Giselle; UEMURA, Margareth M.; SUTTI, Weber; DIOGO, Erica C. Planejamento Integrado para as cidades históricas. XIV Encontro Nacional da Anpur, 2011, v.14, pp.2-20. Disponível em: <http://unuhospedagem.com.br/revista/rbeur/index. php/anais/article/view/2881/2818>. Acesso em 17 abr. 2015.

MONTALVÃO, Cláudia Soares de Azevedo. Do Paço ao Museu: o Museu Imperial e a instituição da memória da Monarquia brasileira (1940-1967). Tese de doutorado. Rio de Janeiro: ifcs-ufrj, Rio de Janeiro, 2005.

MORAES, Nilson. Políticas públicas, políticas culturais e museu no Brasil. Revista Museologia e Patrimônio, v.ll, n.1, jan./jun.2009. Disponível em: <http://revistamuseologiaepatrimonio.mast.br/index.php/ppgpmus/article/viewFile/46/26>. Acesso em 16 abr. 2015. 
MICELI, Sérgio. Teoria e prática da política cultural oficial no Brasil. In: (Org.). Corpo e alma do Brasil. São Paulo: Difel, 1984, pp.53-8; 97-111.

PLANO DIRETOR DE PETRÓPOLIS DE 2013. Disponível em: <http://www.petropolis.rj.gov.br/pmp/phocadownload/Planejamento/comcidade/Minuta_de_\%20Lei_ PDP.pdf>. Acesso em 17 abr. 2015.

PLANO DIRETOR DO TURISMO DE PETRÓPOLIS DE 2009. Disponível em: <http:// pt.scribd.com/doc/220577069/Plano-Imperial\#scribd>. Acesso em: 17 abr. 2015.

PROPOSTA DE PLANO MUNICIPAL DE CULTURA DE PETRÓPOLIS DE 2011 A 2020. 2010. Disponível em: <https://culturaecomunicacaosocial.files.wordpress.com/2012/04/ proposta-final-do-pmc.pdf>. Acesso em 17 abr. 2015.

RIBEIRO, Ana C. T. Oriente negado: cultura, mercado e lugar. Cadernos ppg-au/ufrba, v.3, Edição Especial (2004), Territórios Urbanos e políticas culturais, pp.97-107. Disponível em: <http://www.portalseer.ufba.br/index.php/ppgau/article/view/1689>. Acesso em 17 abr. 2015.

RUBIM, Antonio A. C. Políticas culturais no Brasil: tristes tradições. Revista Galáxia, São Paulo, n.13, pp.101-13, jun.2007. Disponível em: <http://revistas.pucsp.br/index.php/galaxia/article/view/1469>. Acesso em 17 abr. 2015.

SANTOS, Myrian S. dos. Museus brasileiros e política cultural. RBCS, v.19, n.55 jun.2004, pp.53-73. Disponível em: <http://www.scielo.br/pdf/rbcsoc/v19n55/ a04v1955>. Acesso em 17 abr. 2015.

SILVA, Agnaldo G. da. Petrópolis: idealismo e inovações na gênese de uma cidade no Brasil-Império. Dissertação de mestrado. Rio de Janeiro: ippur, 2000. 